\title{
Inelastic behavior and mechanical strength of the shallow upper crust controlled by layer-parallel slip in the high-strain zone of the Niigata region, Japan
}

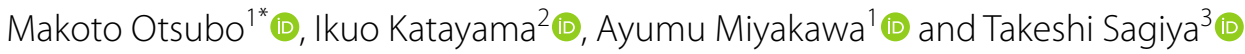

\begin{abstract}
We investigated the relationship between contractional deformation of sedimentary mass in the upper crust and the geodetic strain rate in a high-strain zone (part of the Niigata-Kobe Tectonic Zone) of the mid-Niigata region, Central Japan. We observed numerous examples of layer-parallel slip (bedding-plane slip) generated by folding. The slip layers have an average spacing of $\sim 3.6 \mathrm{~m}$ (measured normal to bedding planes) at the Katagai site. In shallow sedimentary units of the upper crust, numerous bedding-plane slip events act to reduce the mechanical strength (effective elastic thickness) of sedimentary rocks under contractional deformation. The results support an existing model, based on geodetic observations, of mechanical decoupling between the weak sedimentary layers and basement. On the layer-parallel slip, we measured the friction coefficient of gouge generated by bedding-plane slip and of mud around non-slip surfaces using double-direct shear tests, and found no difference in frictional coefficient between slip and non-slip surfaces.
\end{abstract}

Keywords: Active fold, Bedding-plane slip, Buckling, Deformation, Niigata-Kobe Tectonic Zone

\section{Introduction}

The Quaternary tectonics of the Japan island arc is characterized by the strong crustal deformation for which the mode and rate differ substantially from those of the late Pliocene. The Niigata-Kobe Tectonic Zone (NKTZ; Fig. 1) has been identified as a high-strain zone in central Japan and shows marked E-W shortening, but there is a discrepancy between the geodesic strain rate $\left(10^{-7} /\right.$ year; Sagiya et al. 2000) and the geological strain rate $\left(10^{-8} /\right.$ year; Wesnousky et al. 1982). Comparison of the dynamic response of the NKTZ with the deformation before and after the 11 March $2011 M_{\mathrm{w}}=9.0$ megathrust earthquake (herein the 2011 Tohoku-oki earthquake)

\footnotetext{
*Correspondence: otsubo-m@aist.go.jp

1 Geological Survey of Japan, AIST, Tsukuba Central 7, 1-1-1 Higashi,

Tsukuba 305-8567, Japan

Full list of author information is available at the end of the article
}

based on continuous GPS data has allowed inelastic deformation in the northern NKTZ to be recognized (e.g., Meneses-Gutierrez and Sagiya 2016). MenesesGutierrez and Sagiya (2016) showed that the short wavelength patterns of the strain rate on the E-W direction reveal a persistent localized contraction zone with the inelastic deformation around northern NKTZ before and after the 2011 Tohoku-oki earthquake. In contrast to the rapid or instantaneous changes corresponding to the elastic response during a seismic cycle, inter- and postseismic deformation patterns reflect a cumulative deformation process (Meneses-Gutierrez and Sagiya 2016). Meneses-Gutierrez et al. (2018) explained present crustal deformation in the mid-Niigata region in terms of (1) the contribution from both elastic and inelastic behaviors and (2) the existence of mechanical decoupling between weak sedimentary layers and basement. Those authors suggested that the difference in strain rates before and 


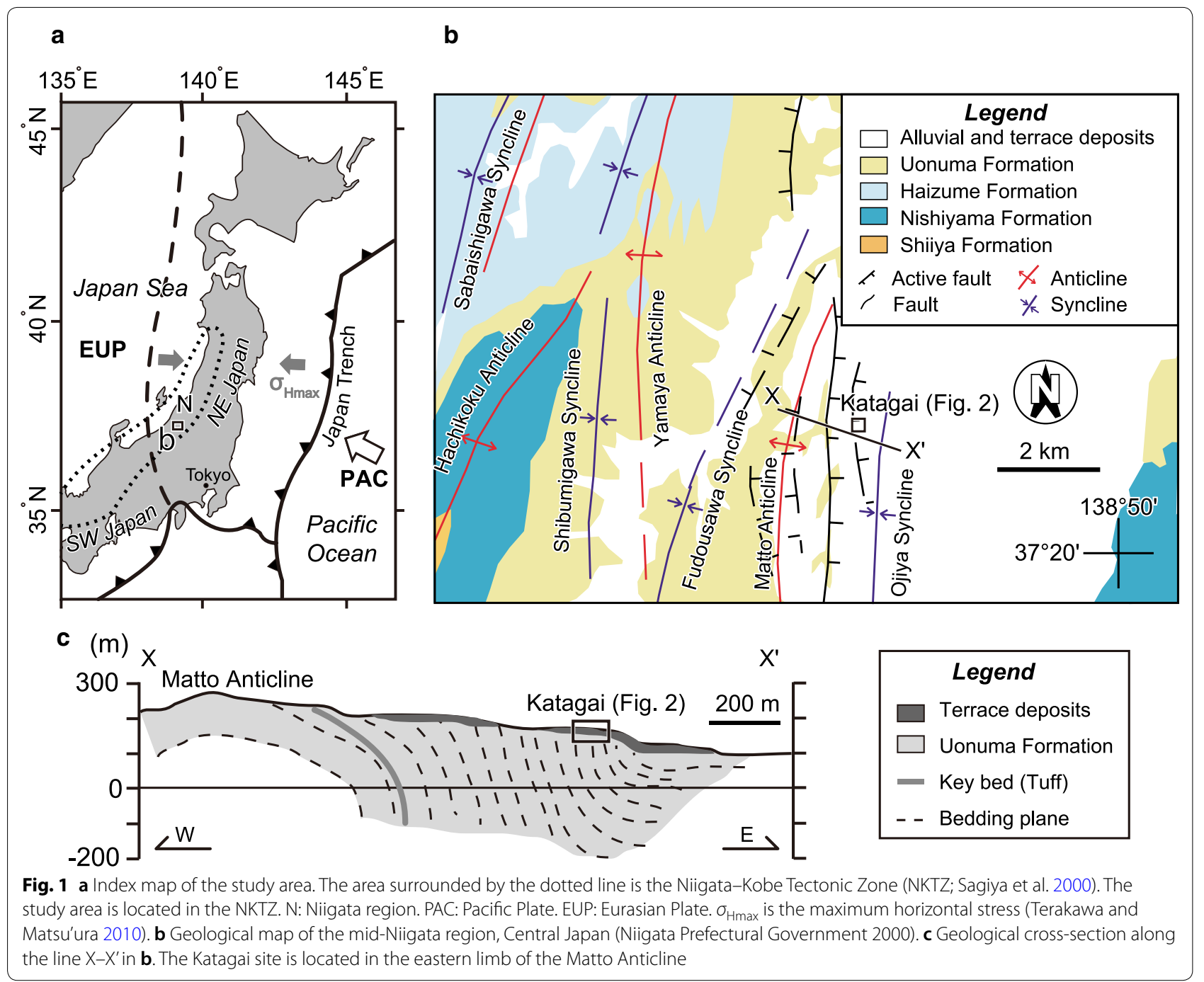

after the 2011 Tohoku-oki earthquake represents the direct influence of the shallow part of the upper crust in the Niigata region.

However, the mechanical strength of the sedimentary layers constituting the shallow part of the upper crust in the Niigata region is not well understood. Here, we focus on deformation of the sedimentary layers by folding. Many active folds have developed in the central Niigata region in response to shortening deformation (e.g., Ota and Suzuki 1979; Fig. 1). The occurrence of layerparallel slip has been reported in these folds (Yamada et al. 1992; Yoshioka 1988, 1989; Ikeda and Yamaji 2008; Otsubo and Yamaji 2010). Multiple sedimentary layers can function as flexural-slip surfaces during folding deformation (e.g., Twiss and Moores 1992). Furthermore, the bedding-plane slip can reduce the mechanical strength (effective elastic thickness) of sedimentary rocks under contractional deformation (Pollard and Johnson 1973; Jackson and Pollard 1988). Therefore, the spacing of layer-parallel slip in sedimentary units is the key to understanding the mechanical strength of the shallow crust in the mid-Niigata region. And, to understand which layers are selectively slipping, it is necessary to examine the differences of frictional coefficients between slip surfaces and non-slip surfaces together with the observation of the slip surface.

In this study, we investigated the relationship between (1) the reduction in mechanical strength of the shallow crust resulting from layer-parallel slip under shortening, and (2) the geodetic strain rate in the mid-Niigata region. First, we measured the spacing of layer-parallel slip surfaces at a large outcrop of an active fold in the mid-Niigata region (Figs. 1, 2). We then measured the friction coefficient of the layer-parallel slip on sedimentary planes 


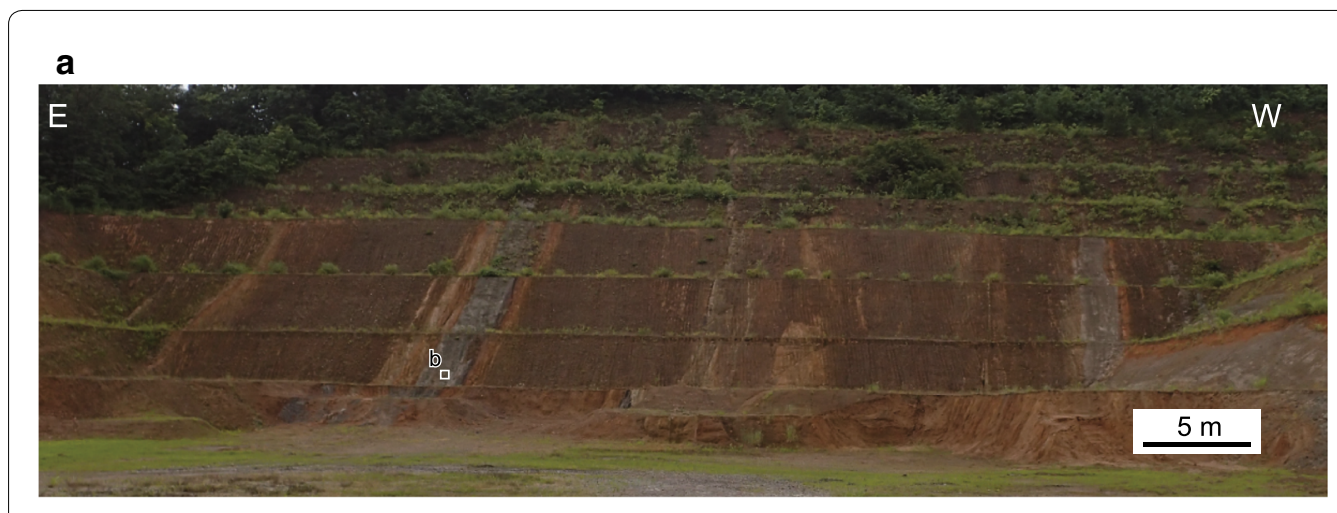

\section{b}
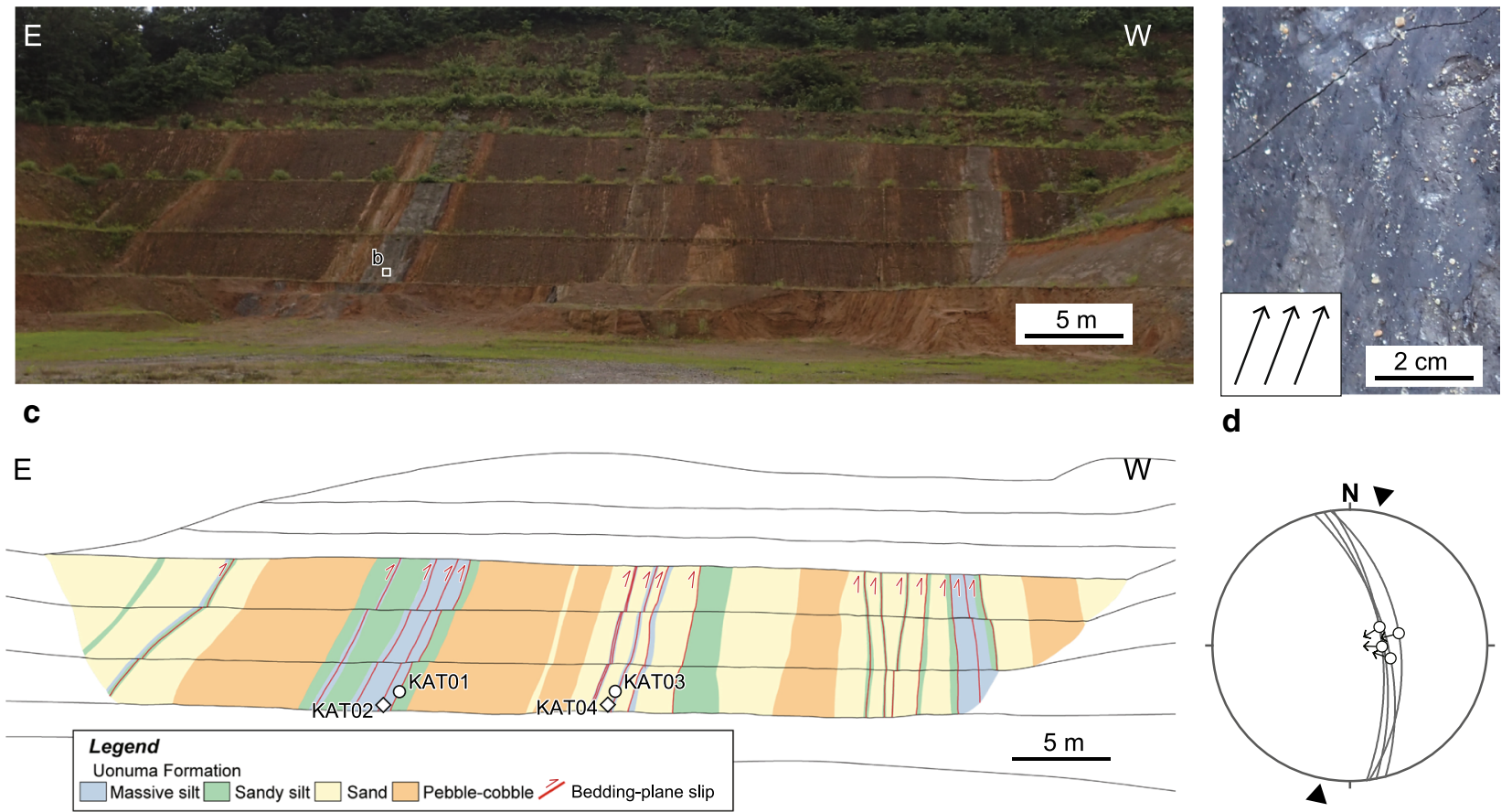

Fig. 2 a Photograph of the outcrop exposure looking south at the Katagai site. The beds of the Uonuma Formation are steeply dipping. $\mathbf{b}$ Photograph of the slickenlines on the slip plane. Inset shows the slip direction of the hanging wall. $\mathbf{c}$ Sketch of the outcrop shown in $\mathbf{a}$. Red lines show slip planes, flexural-slip faults, and reverse faults. The average spacing of bedding-plane slip surfaces at this site is $\sim 4 \mathrm{~m}$. Circles and diamonds indicate sampling sites of fault gouge generated by bedding-plane slip and mudstone, respectively, collected for measurements of the friction coefficient. $\mathbf{d}$ Lower hemisphere, equal-angle stereographic projections of the typical bedding-plane slip at the Katagai site. Triangles indicate the trend of the fold axis of the Matto Anticline

using a biaxial testing machine. Finally, we evaluated the strength of the crustal deformation in this region using a simple two-dimensional buckling model to evaluate the shallow deformation caused by flexural-slip during folding.

\section{Geological setting}

The Niigata sedimentary basin (Fig. 1), one of the largest rift basins in the eastern margin of the Japan Sea, formed mostly during the early Miocene (Yamaji 1990). Neogene sequences were deposited in rifts that formed during the early Miocene concurrently with the opening of the Japan Sea, and these sequences have been folded and faulted by E-W- to NW-SE-compression since the Pliocene (Sato 1994; Okamura et al. 1995). The sediments in the basin are up to $\sim 5000 \mathrm{~m}$ thick and have been folded during the last 2 to 3 Myear (e.g., Niigata Prefecture Government 2000).

We investigated the mid-Niigata basin (Fig. 1), which contains the following major folds (from west to east): the Sabaishigawa Syncline, the Hachikoku Anticline, the Shibumigawa Syncline, the Yamaya Anticline, the
Fudousawa Syncline, the Matto Anticline, and the Ojiya Syncline (Fig. 1). These folds are actively growing in the mid-Niigata region (Otsubo and Miyakawa 2016). The axes of these folds are oriented NNE-SSW or NE-SW, and both longer folds (axial lengths of $10-20 \mathrm{~km}$ and wavelengths of $3-5 \mathrm{~km}$ ) and smaller folds (axial lengths of $2-3 \mathrm{~km}$ and wavelengths of $2-3 \mathrm{~km}$ ) are present. The folds are of kink-fold type with a subhorizontal hinge line and an interlimb angle of $\sim 90^{\circ}$. The average horizontal shortening in the mid-Niigata region has been estimated at about 13\% (Sato 1989). The studied Katagai site (Figs. 1, 2) is located on the eastern limb of the Matto Anticline. The Katagai site provides a high-quality exposure of a cross-section measuring $>50 \mathrm{~m}$ across in the mid-Niigata region and oriented approximately normal to the fold axis of the Matto Anticline (Fig. 1).

Sediments deformed by the anticlines range in age from middle Miocene to Pleistocene (Yanagisawa et al. 1985, 1986; Kobayashi et al. 1988, 1991). Miocene sediments are composed mainly of mudstone and turbidites that were deposited in deep- to shallowmarine environments. Pliocene sediments comprise a 
coarsening-upward sequence that thickens to the west, indicating deposition on a westward-deepening slope along the eastern margin of the rift basin. The Uonuma Formation consists of latest Pliocene-middle Pleistocene fluvial to shallow-marine sediments, and is $2000-2500 \mathrm{~m}$ thick. Numerous tuff beds have been identified as key beds in the Niigata region (Kurokawa 1999). Based on the detailed mapping of the key beds and unconformable contacts, Kishi and Miyawaki (1996) showed that the folding activity has migrated progressively eastward since $3 \mathrm{Ma}$. Growth of anticlines in the study area has continued for < 1 Myear (Kishi and Miyawaki 1996). The east-west horizontal shortening detected with the GPS observation (Sagiya et al. 2000) implies the active shortening in the study area is still ongoing.

\section{Layer-parallel slip during folding}

We identified 36 layer-parallel slip surfaces at the Katagai site on the eastern limb of the northern Matto Anticline (Fig. 2). The outcrop consists of steeply dipping $\left(50^{\circ}-70^{\circ}\right)$ beds of the Uonuma Formation. The Uonuma Formation is overlain unconformably by terrace gravel deposits, on which topsoil has formed. The Uonuma Formation, the terrace deposits, and the topsoil have estimated at the ages of 850, 150-130, and $8 \mathrm{ka}$, respectively (Kishi et al. 1996; Hayatsu and Arai 1982; Suzuki et al. 2008). The recognized bedding-plane slip surfaces show a reverse sense of movement at the Katagai outcrop (Fig. 2). Bedding planes that have accommodated layer-parallel slip can be recognized as the planar surfaces where slight roughness has disappeared. Most observations of surface slip were made at the interfaces between siltstone and mudstone layers. Slickenside striations are present on all faults and indicate approximately dip-slip movement (Fig. 2b). Fault movement directions are approximately perpendicular to the hinge of the Matto Anticline. Asymmetric microstructures on fault surfaces (Petit 1987) were used to determine the sense of slip, including the "comet patterns" made by micro-breccia on these surfaces (e.g., Mino et al. 2001). The identified slip surfaces have bedding-plane-normal spacings of $\sim 3.6 \pm 0.7 \mathrm{~m}$ (Standard error of 36 layer-parallel slip surfaces, Fig. 3).

\section{Shear experiments to determine the friction coefficient}

We measured the friction coefficient of gouge generated by bedding-plane slip and that of mud around non-slip surfaces (Fig. 4). Double-direct shear tests of four disaggregated samples (KAT01, 02, 03, and 04) on two sliding planes were performed at a constant velocity of $3.0 \mu \mathrm{m} / \mathrm{s}$ under dry and room temperature conditions (see Kawai et al. 2015 for experimental details). In all experiments, the applied normal stress was 12, 23, 35, and $46 \mathrm{MPa}$ during sliding, and samples were sheared up at least four

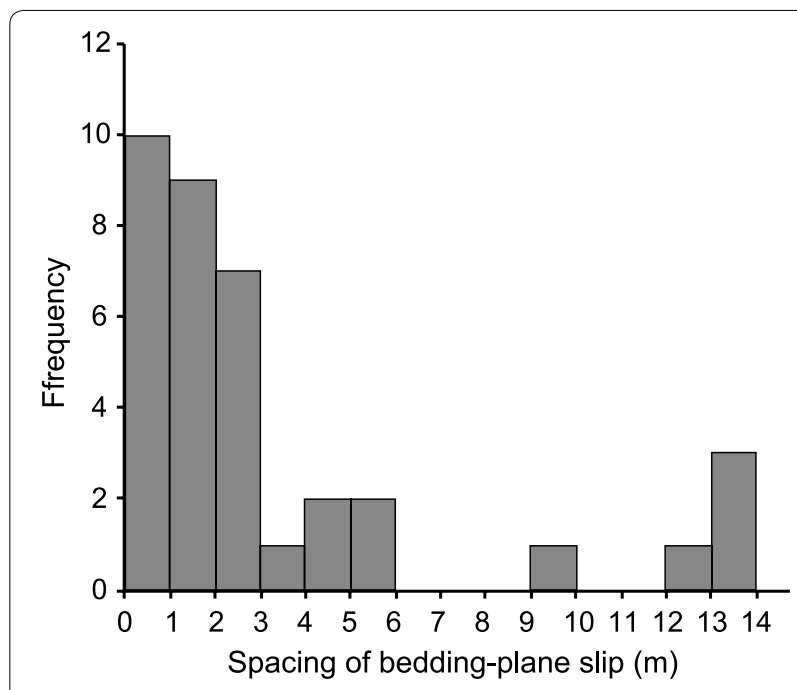

Fig. 3 Histogram showing the frequency distribution of the spacing of bedding-plane slip at the Katagai site

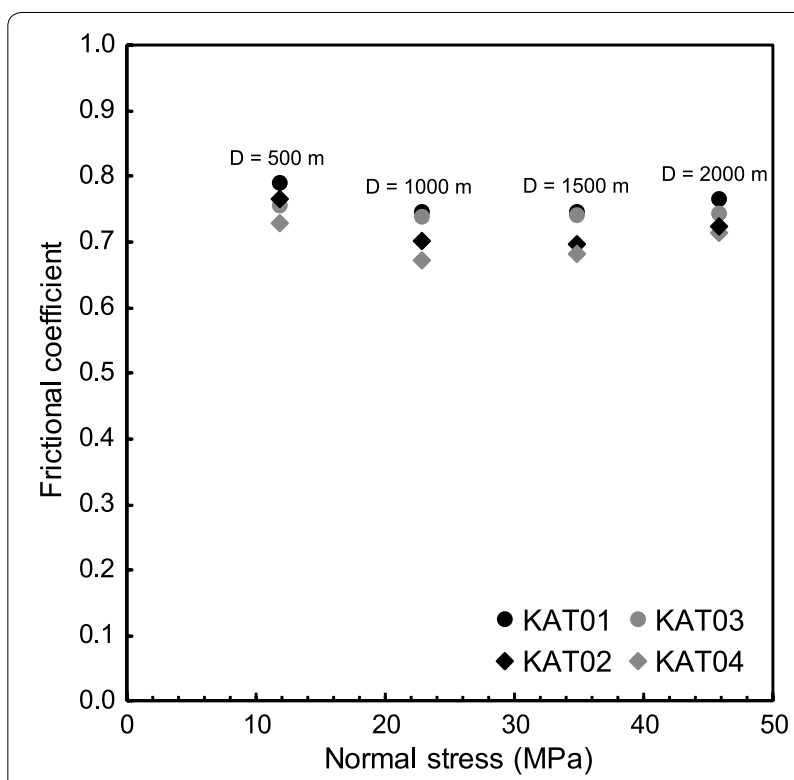

Fig. 4 Friction coefficients of fault gouges (KAT01, 03) generated by bedding-plane slip and of mudstones (KAT02, 04). Double-direct shear tests of four samples (KAT01, 02, 03, and 04) on two sliding planes were performed as in previous studies (Kawai et al. 2015). D: Depth

times at each normal stress to achieve a steady-state friction. These normal stresses correspond to shallow crustal depths of $0.5,1.0,1.5$, and $2.0 \mathrm{~km}$, respectively (density of the Uonuma Formation $=2360 \mathrm{~kg} / \mathrm{m}^{3}$; Hoshino et al. 2001).

Figure 4 shows the results of the frictional experiments for the four samples. The friction coefficient $(\mu)$ 
was calculated by dividing the shear stress by the normal stress assuming zero cohesion. The estimated friction coefficients at steady state were $0.74-0.79,0.74-0.75$, $0.70-0.76$, and $0.67-0.73$ for normal stresses for samples KAT01, 02, 03, and 04, respectively (Fig. 4).

\section{Estimation of effective elastic thickness}

We estimated the strength of shallow sedimentary units under contraction in the mid-Niigata region using a two-dimensional buckling model. In general, the bending moment, $M$, of the elastic plate is proportional to the curvature, $K$, of plate so that

$$
M=-D K
$$

where $D$ is the flexural rigidity of a plate and is the constant of proportionality. Following Pollard and Johnson (1973) and Jackson and Pollard (1988), we employed $D$ as follows:

$$
D=\frac{Y t_{\mathrm{e}}^{3}}{12\left(1-v^{2}\right)}
$$

where $Y$ is Young's modulus, $v$ Poisson's ratio, and $t_{\mathrm{e}}$ the elastic thickness. The value of $D$ was estimated for each plate to characterize the resistance to bending. The quantity $t_{e}$ is the thickness assuming that the sedimentary units act as an elastic plate. Here, we consider a plate composed of two thick elastic layers; i.e., a composite plate. In this model, no friction is assumed on the boundary between layers. From Eq. (2), the flexural rigidity of a composite plate is

$$
\begin{aligned}
D & =\frac{Y}{12\left(1-v^{2}\right)}\left[\left(\frac{t_{\mathrm{e}}}{2}\right)^{3}+\left(\frac{t_{\mathrm{e}}}{2}\right)^{3}\right] \\
& =\frac{Y}{12\left(1-v^{2}\right)} 2\left(\frac{t_{\mathrm{e}}}{2}\right)^{3}=\frac{Y}{12\left(1-v^{2}\right)}\left(\frac{t_{\mathrm{e}}}{\sqrt[3]{4}}\right)^{3} .
\end{aligned}
$$

As $1 / \sqrt[3]{4} \fallingdotseq 0.63$, a plate composed of two equally thick elastic layers has an effective elastic thickness of about $63 \%$ of the thickness of a plate. It is obvious from the above argument that when a composite plate comprises many layers, its effective elastic thickness, $t_{e}$, satisfies

$$
t_{e}^{3}=t_{1}^{3}+t_{2}^{3}+\cdots+t_{n}^{3},
$$

where $t_{i}$ is the thickness of the $i$ th layer. The effective elastic thickness decreases as $t_{\mathrm{e}}=n^{-2 / 3}(n t)$ when the plate is divided into $n$ layers with the same thickness $t$ and the same elastic constant (Fig. 5). Therefore, the flexuralshear folding occurs readily in sedimentary piles (Jackson and Pollard 1988). The thickness of the deformed layer in the mid-Niigata basin is $\sim 5000 \mathrm{~m}$ (Niigata Prefecture Government 2000), and this layer is regarded

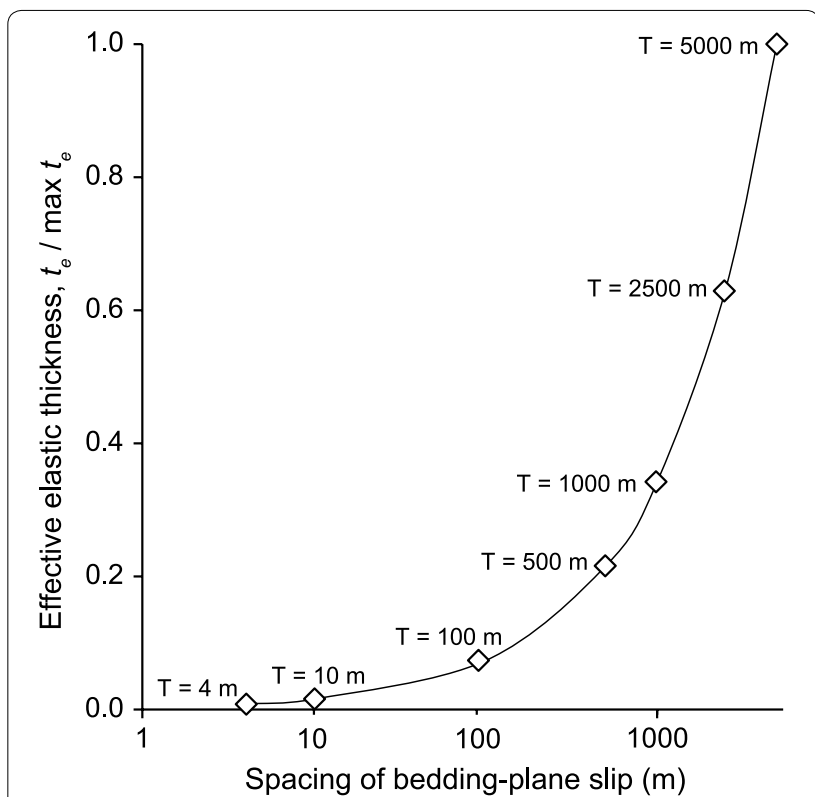

Fig. 5 Relationship between the effective elastic thickness and the spacing of bedding-plane slip surfaces. In the case of the maximum elastic thickness, the sedimentary mass contains no bedding-plane slip surfaces. In the sedimentary units, the numerous bedding-plane slip surfaces act to reduce the mechanical strength (effective elastic thickness) of sedimentary rocks under contractional deformation. T: Thickness of a bed as an elastic layer

here as the effective elastic thickness $t_{\mathrm{e}} . Y$ and $v$ were regarded as constant during folding. The average spacing of bedding-plane slip surfaces is $\sim 4 \mathrm{~m}$ at the Katagai site, meaning that the sedimentary rock mass can be divided into $n=1250$ elastic layers, whereby the effective elastic thickness decreases to $<0.01 \%$ of the elastic thickness of $\sim 5000 \mathrm{~m}$ using $n=1250$ at the Katagai site (Fig. 5).

\section{Discussion}

We observed numerous layer-parallel slip surfaces (bedding-plane slip surfaces) generated by folding in the high-strain zone of the Niigata region, Japan (Fig. 2). Bedding-plane slip observations in the study area shed light on the kinematics of folding. The observed slips are consistent with flexural-slip folding, as the slip vectors on slip layers indicate the movement of overlying layers toward the anticline hinge (Fig. 2). The folding is developed under the E-W- to NW-SE-compression in the region. The bedding-plane slip has been reported in the northern part of the Matto Anticline (Ota and Suzuki 1979; Yoshioka 1988, 1989). Yoshioka (1989) reported active bedding-plane slip surfaces cutting terrace deposits near the study area, suggesting that the Matto Anticline remains active (Kobayashi et al. 1991; Kishi and Miyawaki 1996). Yoshioka (1989) concluded that active 
folding occurs by flexural folding. Although Yoshioka (1989) described bedding-parallel slip layers, the spacing between layers was unknown. The Katagai site with the exposure of a cross-section measuring $>50 \mathrm{~m}$ is a good place to measure the spacing of bedding-parallel slip in the mid-Niigata region. The spacing between layer-parallel slip layers can be clarified if the layers can be identified using diagnostic criteria (e.g., the planar nature of slip surfaces).

We measured the friction coefficient of the gouge generated by the bedding-plane slip and that of mud around bedding planes under the shallow crustal depths of 0.5 , 1.0, 1.5, and $2.0 \mathrm{~km}$ (Fig. 4). The measurements evaluate the friction of the Uonuma Formation with the thickness of 2000-2500 m. Generally, folds form in strongly layered sequences that have a strong planar mechanical anisotropy (Twiss and Moores 1992). The frictional contact between layers controls the degree of localization of bedding-plane slip within fold limbs (Johnson 2018). The sedimentary layers in the study area have varied lithologies, including lignite, siltstone, sandstone, and conglomerate. Although the layers are individually weak, they might behave as a single multi-layered body. The estimated values of the friction coefficient (0.6-0.8) are consistent with the general values suggested by Byerlee's law (Byerlee 1978). We found no difference in the frictional coefficient between slip surfaces and non-slip surfaces in the Katagai site. These results indicate that the difference of frictional coefficient is not the cause of spacing of the layer-parallel slip but mechanical processes during bending deformation are responsible under the shallow crustal depths of up to $2 \mathrm{~km}$. In future work, it will be necessary to estimate the friction coefficient under the shallow crustal depths of up to $5 \mathrm{~km}$. Furthermore, the same measurement as performed here may hold for other folds in the NKTZ.

We also assessed the contribution of layer-parallel slip to contractional deformation. We considered a folded sedimentary rock with a thickness of $\sim 5000 \mathrm{~m}$ to estimate the critical load. When the rock has the parameters $Y=30 \mathrm{GPa}, v=0.25$, and $t_{\mathrm{e}}=5000 \mathrm{~m}$, then $D=\sim 3.3 \times 10^{20} \mathrm{Nm}$. If the half-wavelength of a fold $L$ is $\sim 2000 \mathrm{~m}$ in the mid-Niigata region (Niigata Prefecture Government 2000), the minimum force needed for folding to occur is $F=\pi D / L^{2}=\sim 8.2 \times 10^{14} \mathrm{~N}$. The average normal stress acting on the sides of the sedimentary rock mass is $F /(5000 \mathrm{~m} \times 1 \mathrm{~m})=\sim 160 \mathrm{GPa}$. In contrast, the average overburden stress is $\sim 120 \mathrm{MPa}$ when the density is $2360 \mathrm{~kg} / \mathrm{m}^{3}$ at a depth of $5000 \mathrm{~m}$. In the case of a single elastic plate, the tectonic force required to buckle sedimentary rock with a thickness of $\sim 5000 \mathrm{~m}$ is thousand times large given the average overburden stress, which is unrealistically large. Hence, without bedding-plane slip, very large crustal stresses are required for flexural deformation. The treatment of the effective thickness of a multi-layer rock is derived for no friction across the layer contacts. The friction of water-saturated clay minerals decreases significantly (Moore and Lockner 2007; Tetsuka et al. 2018). And, the mineralogy and fabric are both important controls on the static frictional strength (e.g., Collettini et al. 2009). In future work, it will be necessary to estimate the friction coefficient under wet conditions and to analyze the effect of clay minerals in detail.

We also investigated the relationship between the reduction in mechanical strength under shortening in the shallow part of the upper crust due to layer-parallel slip and the geodetic strain rate in the mid-Niigata region. In a study of this region, Meneses-Gutierrez et al. (2018) proposed a model of mechanical decoupling between the weak sedimentary layers and basement to explain the short-wavelength response of post-seismic strain rate patterns. The short-wavelength response of post-seismic strain rate patterns can be explained by the elastic weakness of the shallow part of the upper crust in the Niigata region, which is $60-70 \%$ weaker than normal crust (Meneses-Gutierrez et al. 2018). Our results (Fig. 5) support the model of Meneses-Gutierrez et al. (2018) outlined above. Hence, the decrease in the strength of the shallow part of the upper crust in the NKTZ can be explained by folding with layer-parallel slip. The same evaluation as performed here may hold for other folds in the NKTZ. Furthermore, it may be useful to discuss a relation of flexural slip and a growth of active fold geodetically observed in this area (e.g., Nishimura et al. 2008; Tsukuda et al. 2008; Nishimura 2010). The outcrop scale deformation with layer-parallel slip must be applicable to the deformation observed by InSAR and leveling.

\section{Abbreviation \\ NKTZ: Niigata-Kobe Tectonic Zone.}

\section{Acknowledgements}

We thank Dr. K. Oohashi and Dr. K. Ujiie for fruitful discussions. Comments by anonymous reviewers improved the manuscripts.

\section{Authors' contributions}

$\mathrm{MO}$ led and designed the research and drafted the manuscript. MO and AM measured the spacing of layer-parallel slip surfaces. MO and IK measured the friction coefficient using double-direct shear tests. MO and TS contributed to the discussion of the inelastic strain in the NKTZ. All authors read and approved the final manuscript.

Funding

This study was supported by MEXT KAKENHI (Number 26109003).

Availability of data and materials

Geological data are available from the authors upon request. 


\section{Competing interests}

The authors declare that they have no competing interests.

\section{Author details}

${ }^{1}$ Geological Survey of Japan, AIST, Tsukuba Central 7, 1-1-1 Higashi, Tsukuba 305-8567, Japan. ${ }^{2}$ Department of Earth and Planetary Systems Science, Hiroshima University, Higashi, Hiroshima 739-8526, Japan. ${ }^{3}$ Disaster Mitigation Research Center, Nagoya University, Nagoya 464-8601, Japan.

Received: 27 September 2019 Accepted: 22 February 2020

Published online: 04 March 2020

\section{References}

Byerlee J (1978) Friction of rocks. Pure Appl Geophys 116:615-626. https://doi. org/10.1007/BF00876528

Collettini C, Niemeijer A, Viti C, Marone C (2009) Fault zone fabric and fault weakness. Nature 462:907-910

Hayatsu K, Arai F (1982) Formation age and rate of deformation of fluvial terraces along the lower stream of the Shinano River, Northeast Japan. Geogr Rev Jpn 55:130-138 (in Japanese with English abstract)

Hoshino K, Kato H, Tanaka S, Omata A, Moriguchi Y, Hattori M, Imamura T (2001) Handbook of mechanical properties of the Japanese rocks under high confining pressure. Geological. Survey of Japan Interim Report No. 23, AIST. (in Japanese with English abstract)

Ikeda M, Yamaji A (2008) The timing of formation of the Higashiyama Anticline, Niigata Prefecture, Central Japan: constraints from Paleocurrent and Geologic Structure. J Geol Soc Jpn 114:405-414 (in Japanese with English abstract)

Jackson MD, Pollard DD (1988) The laccolith-stock controversy: new results from the southern Henry Mountains, Utah. Geol Soc Am Bull 100:117-139

Johnson KM (2018) Growth offault-cored anticlines by flexural slip folding: analysis by boundary element modeling. J Geophys Res Solid Earth 123:2426-2447. https://doi.org/10.1002/2017JB014867

Kawai K, Sakuma H, Katayama I, Tamura K (2015) Frictional characteristics of single and polycrystalline muscovite and influence of fluid chemistry. J Geophys Res Solid Earth 120:6209-6218

Kishi K, Miyawaki R (1996) Plio-Pleistocene fold development in the Kashiwazaki Plain and vicinity, Niigata Prefecture. J Geogr (Chigaku Zasshi) 105:88-112 (in Japanese with English abstract)

Kishi K, Miyawaki R, Miyawaki A (1996) The stratigraphy and paleoenvironmental reconstruction of the late Pleistocene deposits in Kashiwazaki Plain, Niigata Prefecture. Quat Res 35:1-16 (in Japanese with English abstract)

Kobayashi I, Tateishi M, Kurokawa K, Yoshimura T, Kato H (1988) Geological map of Japan 1:50000, Okanomachi district. Geological Survey of Japan, AIST (in Japanese)

Kobayashi I, Tateishi M, Yoshioka M, Shimazu M (1991) Geological map of Japan 1:50000, Nagaoka district. Geological Survey of Japan, AIST (in Japanese)

Kurokawa K (1999) Tephrostratigraphy of the Nanatani to Uonuma formations of $13 \mathrm{Ma}$ to $1 \mathrm{Ma}$ in the Niigata region, central Japan. J Jpn Assoc Petrol Technol 64:80-93 (in Japanese with English abstract)

Meneses-Gutierrez A, Sagiya T (2016) Persistent inelastic deformation in central Japan revealed by GPS observation before and after the Tohoku-oki earthquake. Earth Planet Sci Lett 450:366-371. https://doi.org/10.1016/j. epsl.2016.06.055

Meneses-Gutierrez A, Sagiya T, Sekine S (2018) Crustal deformation process in the mid-Niigata region of the Niigata-Kobe Tectonic Zone as observed by dense GPS network before, during, and after the Tohoku-oki earthquake. J Geophys Res Solid Earth 123:6072-6085. https://doi.org/10.1029/2018J B015567

Mino K, Yamaji A, Ishikawa N (2001) The block rotation in the Uetsu area, northern part of Niigata Prefecture, Japan. Earth Planets Space 53:805-815. https://doi.org/10.1186/BF03351678

Moore DE, Lockner DA (2007) Friction of the smectite clay montmorillonite. In: Dixon T, Moore C (eds) The seismogenic zone of subduction thrust faults. Columbia University Press, New York, pp 317-345

Niigata Prefecture Government (2000). Geological map of the Niigata Prefecture. Niigata Prefecture (in Japanese)
Nishimura T (2010) Crustal deformation of the Niigataken Chuetsu-oki earthquake in 2007 and coincident growth of active fold clarified by geodetic measurements. Active Fault Res 32:41-48 (in Japanese with English abstract)

Nishimura T, Tobita M, Yarai H, Amagai T, Fujiwara M, Une H, Koarai M (2008) Episodic growth of fault-related fold in northern Japan observed by SAR interferometry. Geophys Res Lett 35:L13301. https://doi. org/10.1029/2008GL034337

Okamura Y, Watanabe M, Morijiri R, Satoh M (1995) Rifting and basin inversion in the eastern margin of the Japan Sea. Island Arc 4:166-181

Ota Y, Suzuki I (1979) Notes on active folding in the lower reaches of the Shinano River, central Japan. Geogr Rev Jpn 52:592-601 (in Japanese with English abstract)

Otsubo M, Miyakawa A (2016) Landward migration of active folding based on topographic development of folds along the eastern margin of the Japan Sea, northeast Japan. Quat Int 397:563-572

Otsubo M, Yamaji A (2010) Relationship between ground and crustal deformations in the western part of the Oginojo Anticline, synchronous with the 2007 Niigataken Chuetsu-oki Earthquake. J Geol Soc Jpn 116:615-623 (in Japanese with English abstract)

Petit JP (1987) Criteria for the sense of movement on fault surfaces in brittle rocks. J Struct Geol 9:597-608

Pollard DD, Johnson AM (1973) Mechanics of growth of some laccolithic intrusions in the Henry Mountains, Utah, II. Tectonophysics 18:311-354

Sagiya T, Miyazaki S, Tada T (2000) Continuous GPS array and present-day crustal deformation of Japan. Pure Appl Geophys 157:2303-2322

Sato H (1989) Degree of deformation of late Cenozoic Strata in the northeast Honshu Arc. Mem Geol Soc Japan 32:257-268 (in Japanese with English abstract)

Sato H (1994) The relationship between late Cenozoic tectonic events and stress field and basin development in northeast Japan. J Geophys Res Solid Earth 99:22261-22274

Suzuki I, Ota Y, Azuma T (2008) Interpretation of various types of active fault on large exposures within a fold and thrust belt at the eastern limb of the Tokimizu Anticline in central Japan. J Geogr (Chigaku Zasshi) 117:637-649 (in Japanese with English abstract)

Terakawa T, Matsura M (2010) The 3-D tectonic stress fields in and around Japan inverted from centroid moment tensor data of seismic events. Tectonics 29:TC6008. https://doi.org/10.1029/2009TC002626

Tetsuka H, Katayama I, Sakuma H, Tamura K (2018) Effects of humidity and interlayer cations on the frictional strength of montmorillonite. Earth Planets Space 70:56. https://doi.org/10.1186/s40623-018-0829-1

Tsukuda T, Takada T, Yanagisawa K (2008) Present-day active folding in the Ojiya Region, Niigata Prefecture, Central Japan, revealed by data from leveling measurements collected over 30 years. Bull Earthq Res Inst Univ Tokyo 83:203-215 (in Japanese with English abstract)

Twiss RJ, Moores EM (1992) Structural geology. W H Freeman and Company, New York

Wesnousky SG, Scholz CH, Shimazaki K (1982) Deformation of an island arc: rates of moment release and crustal shortening in intraplate Japan determined from seismicity and Quaternary fault data. J Geophys Res Solid Earth 87(B8):6829-6852. https://doi.org/10.1029/JB087iB08p06829

Yamada Y, Hattori M, Kuniyasu M (1992) Inversion tectonics of the Niigata oil fields. Struct Geol 38:59-72 (in Japanese with English abstract)

Yamaji A (1990) Rapid intra-arc rifting in Miocene northeast Japan. Tectonics 9:365-378

Yanagisawa Y, Chihara Y, Suzuki Y, Uemura T, Kodama K, Kato T (1985) Geological map of Japan 1:50000, Tokamachi district. Geological Survey of Japan, AIST

Yanagisawa Y, Kobayashi K, Takeuchi K, Tateishi M, Chihara K, Kato K (1986) Geological map of Japan 1:50000, Ojiya district. Geological Survey of Japan, AIST

Yoshioka T (1988) Active faults in the active fold belt. Chishitsu News 411:6-9 (in Japanese)

Yoshioka T (1989) Flexural-slip faults related to folding. Active Fault Res 7:5-12 (in Japanese)

\section{Publisher's Note}

Springer Nature remains neutral with regard to jurisdictional claims in published maps and institutional affiliations. 